\title{
Development of Centralize E-Learning Assignment System with Asp.Net at PT. Epson Batam
}

\author{
Henky Pramulia $^{1}$, Syahril $^{2}$, Refdinal $^{3}$, B. Herawan Hayadi ${ }^{4}$, Hendri $^{5}$ \\ Master of Technology and Vocational Education Masters Program, Faculty of Engineering, \\ Padang State University ${ }^{1,2,3}$ \\ University of Pasir Pengaraian, Riau Indonesia ${ }^{4,5}$ \\ $\left\{\right.$ henky.pramulia@gmail.com $\left.{ }^{1}\right\}$
}

\begin{abstract}
The electronic-based learning method is a learning process using Information and Communication Technology (ICT) as a tool that can overcome learning problems without being limited by space and time. Companies from small, medium to large scale begin to see the importance and benefits of ELearning. PT. Epson Batam is a company engaged in electronics located in Batam. To support the improvement of human resource capacity at PT. Epson Batam, an E-Learning system was implemented. The E-Learning system currently has several limitations, so that the E-Learning system is not optimal in the aim of improving the capabilities and performance of PT. Epson Batam. In this study produce products in the form of developing E-Learning as a learning supplement for learning in the industry, researchers need to determine the right development model in developing the product. Based on the product to be developed, researchers chose the ADDIE (Analysis, Design, Development, Implementation, and Evaluation) development model developed by Dick and Carey. In this research, the software quality evaluation standard used is ISO 9126. For functionality evaluation aspect using questionnaire with ISO 9126 functionality analysis technique, reliability uses WAPT Pro tool with ISO 9126 reliability analysis technique, usability using questionnaire with usability analysis technique ISO 9126, and efficiency using a performance test tool with ISO 9126 efficiency analysis technique. System development is using ASP.NET technology. The system has been tested for quality based on ISO 9126 software quality standards and the results have fulfilled four aspects of quality (Web$\mathrm{QEM}$ ). On the aspect of functionality get a percentage of $100 \%$ with a value of $\mathrm{X}$ $=1$, which means that all functions are running correctly, aspects of reliability get an average percentage of $100 \%$ with successful results, usability aspects get a percentage of $75.7 \%$ or in the category agree with the value Cronbach's Alpha 0.952 is in excellent category, and for the average aspect of efficiency for load time is $582.45 \mathrm{~ms}$, so it can be concluded that the information system Centralize E-Learning assignment system has fulfilled the efficiency aspects of ISO 9126 software quality standards.
\end{abstract}

Keywords: E-Learning, ADDIE development model, ISO 9126 


\section{Introduction}

Currently electronic-based learning methods have been widely applied and accepted by the world community, as evidenced by the many applications of electronic-based learning methods in educational institutions (schools, training centers and universities) and industry (Oracle, IBM, Cisco Systems, Hewlett-Packard, etc.) ) Electronic-based learning method is a type of learning system that allows the delivery of teaching materials to participants using computer network media, and Internet media[1]-[3].

E-Learning, which can be called the electronic-based learning method, is a learning process (learning) using/utilizing Information and Communication Technology (ICT) as a tool that can overcome space and time constraints because it can be available whenever and wherever needed. E-Learning as an alternative solution is new hope for most problems in education in Indonesia, with functions that can be adapted to needs, either as a supplement (additional), complement (complimentary), or substitution for learning activities in the classroom that so far this can be used[4], [5].

To implement E-Learning, there are at least three components to form E-Learning, namely[6]:

1. E-Learning infrastructure, which can be in the form of personal computers (PCs), computer networks, and multimedia equipment.

2. E-Learning systems and applications are software systems that represent conventional teaching and learning processes that include how classroom management, material or content creation, discussion forums, scoring systems, examination systems and all features related to the management of teaching and learning processes. The software system is often called the Learning Management System (LMS).

3. E-Learning content is teaching material that is on the E-Learning system (Learning Management System). This content and teaching material can be in the form of multimedia-based content (content in the form of interactive multimedia) or text-based content (content in the form of text as in ordinary textbooks). E-Learning content is usually stored in the LMS so that it can be accessed by users wherever and whenever.

While the participants in the implementation of E-Learning in principle are the same as the conventional teaching and learning process, namely the need for guiding instructors, administrators who manage the administration and teaching and learning processes and participants who receive teaching materials[7].

Accompanying the rapid development trends and E-Learning needs, there is a need for a generally accepted standard. For this reason, several institutions have made efforts to develop standards for the implementation of E-Learning, namely[8] :

1. Airline Industry CBT Committee (AICC), with a standard focus on flight training, such as tests, lessons, modules, etc.

2. EDUCAUSE The Institutional Management System Project (IMS) is a group of vendors working to establish standards for work at the AICC (www.imsglobal.org)

3. Advanced Distributed Learning (ADL), initiated by the federal government of the USA working to develop SCORM.

4. Alliance of Remote Institutional Authoring and Distribution Network for Europe (ARIADNE) is an industry association that focuses on issues for standardization of ELearning.

5. IEEE Learning Technology Standards Committee (IEEE LTSC) is an accreditation standard in the USA.

6. ISO / IEC JTC1 SC36 (ITLET) is an ICT standard for learning, education, and training 
7. Advanced Learning Infrastructure Consortium (ALIC), is a consortium in Japan to promote E-Learning technology and infrastructure.

8. E-Learning Consortium Japan (eLC) is a company (vendor/user) that works to promote ELearning business and technology in Japan.

According to elearningindustry.com data, the online education industry (e-learning) in Indonesia ranks 8th in the world based on the total E-Learning market. Still, according to the same data, the level of online education needs or e-learning is increasing every year, especially coming from corporations in Indonesia[9].

Companies from small, medium to large scale begin to see the importance and benefits of ELearning. Recorded according to elearningindustry.com data, the E-Learning market for companies globally grew by $13 \%$ per year. Meanwhile, according to data and statistics from the 2014 Training Industry Report, 29\% of companies globally, both small, medium and large, are interested in buying software and E-Learning services. Also, 41\% of companies are interested in buying a Learning Management System (LMS) services[10].

\section{Method}

In the research and development of information systems, centralize the e-learning assignment system with ASP.net at Epson Batam Batam using Research and Development (R \& D) research methods. R \& D is a research method that aims to produce a particular product and test the effectiveness of the product.

The products produced in this research are information systems centralize web-based elearning assignment systems. For software development, a development model is needed to be called SDLC or System Development Life Cycle. The model used in this study is the ADDIE model (Analysis, Design, Development, Implementation, and Evaluation) developed by Dick and Carey.[11]

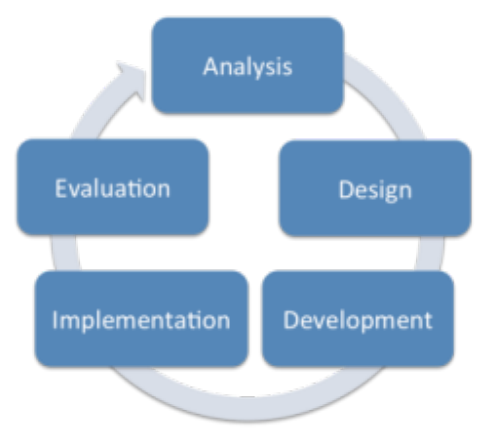

Figure 1. ADDIE Model

\section{Result and discussion}

Taha, The next stage in the ADDIE Model development method, is Design. The design here is intended to make modeling of new applications that can solve problems on E-Learning systems that are currently running at PT. Epson Batam[12]. 
E-Learning Information System process, namely: Admin, Trainer, Participant / User, Supervisor level, Managerial Level funds. In the proposed system, the author distinguishes the entity in detail:

1. Admin has the highest access rights to regulate the provision of access to all entities involved in the E-Learning system and also has the task of being responsible for each general master data contained in the E-Learning system. Inputs that can be done by the admin to the E-Learning system include user registration master data, user level master access data, mass data type question data, master variable data. And for reports that can be obtained by the Admin from E-Learning systems including user registration master report, user level master access report, master type question report, master variable report.

2. The trainer has access to authority that is responsible for the dissemination of material and assignments contained in E-learning. Inputs that can be done by trainers to E-Learning systems include reg material data, reg assignment data, participant/user data, question bank data. And for reports that can be obtained by trainers from E-Learning systems including reports on the distribution of material, reports on assignment deployment, reports on authorization status of superiors, reports on participant results, reports on the recapitulation of participants' scores.

3. Participants / Users have access and are responsible for the material that has been distributed to participants from the trainers and assignments that have been distributed to participants from trainers through the E-Learning system. Inputs that can be done by participants/users to the E-Learning system include material access data, assignment data filling. And for reports that can be obtained by participants/users of the E-Learning system including participant report results.

4. Supervisor level has access and is responsible for the material that has been submitted by the trainer to the approval of level 1 authorization, namely the supervisor level before the material and assignments are distributed to participants through the E-Learning system. Inputs that can be done by the supervisor level to the E-Learning system include Level 1 approval. And for reports that can be obtained by the supervisor level from the ELearning system, including report on the authorization status of the supervisor, material distribution or assignment, participant reports include material access report and report on assignment results, report recapitulation of participants' assignment value.

5. Managerial level has access and is responsible for material that has been submitted by trainers to the approval of level 1 authorization, namely supervisor level and approval of level 2 authorization, namely managerial level before the material and assignments are distributed to participants through an E-Learning system. Inputs that can be done by managerial level to E-Learning systems include Level 2 approval. And for reports that can be obtained by managerial level from E-Learning system, including report on participant results including material access reports, and assignment report, value recapitulation report assignment of participants.

Entity Relationship Diagram: 


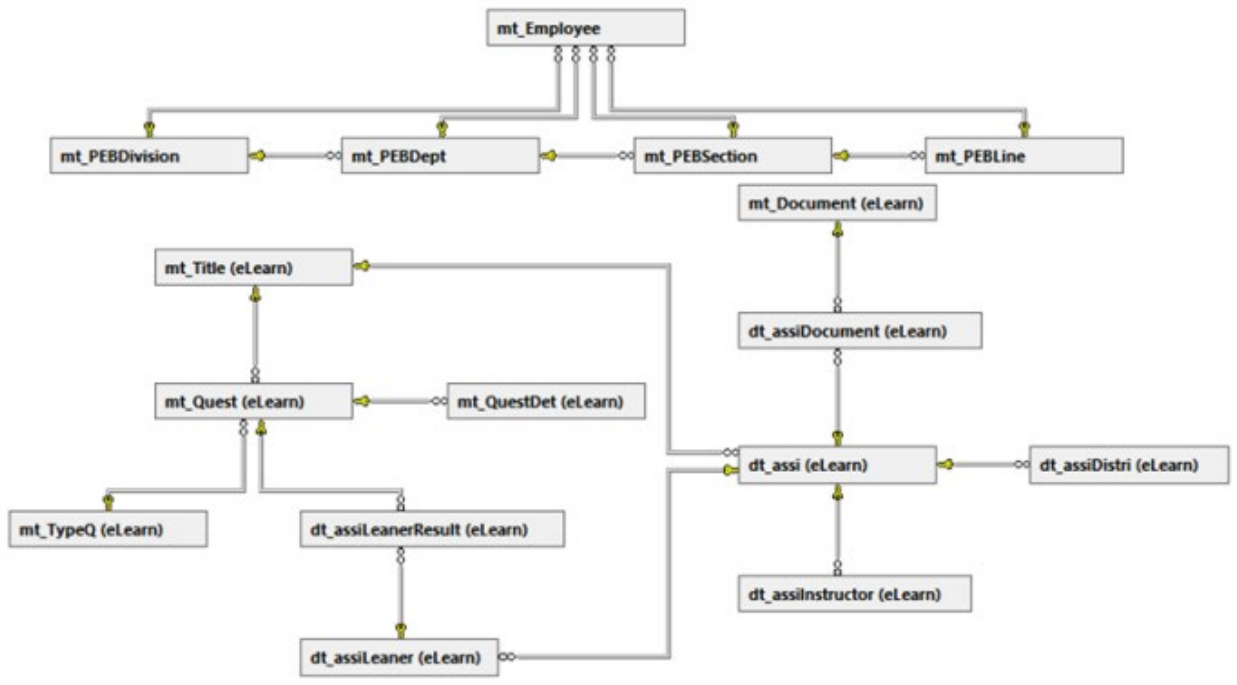

Figure 2. Entity Relationship Diagram (ERD)

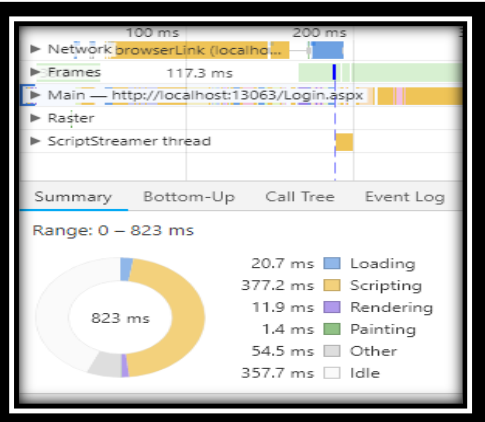

Figure 3. Test results of login efficiency

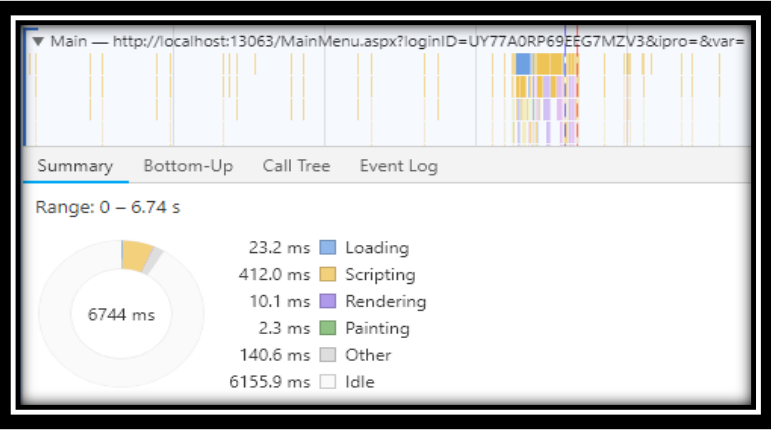

Figure 4. Test results of efficiency My Assignment - Document Support 


\section{Conclusion}

Based on the results of the research and the discussion that the researchers did, it can be concluded that:

a. Development of information systems of Centralize E-Learning assignment systems are carried out using ASP.NET technology of C \# programming language and Sql Server 2012. Microsift database. After the development or coding phase, then publishing will be done to the company's internal web server (IIS 7.0). The development of this information system aims to assist in enhancing human resource capabilities at PT. Epson Batam.

b. Centralize E-Learning information system assignment system has been tested for quality based on ISO 9126 software quality standards and the results have met four aspects of quality (Web-QEM). On the functionality aspect, get a percentage of $100 \%$ with a value of $\mathrm{X}=1$, which means that all functions are running correctly, reliability aspects get an average percentage of $100 \%$ with SUCCESS results, usability aspects get a percentage of $75.7 \%$ or in the category agree with the value Cronbach Alpha 0.952 which is in the excellent category, and for aspect efficiency for the load time the average is $582.45 \mathrm{~ms}$. Based on the standards of machmetrics.com with the types of Business \& Industrial Markets Japan that must be below $8.1 \mathrm{~s}$, the average load time of information systems Centralize the E-Learning assignment system is good, where users can still stay focused on using the web and not be disturbed with a long load time, so it can be concluded that Centralize ELearning assignment system information system has met the efficiency aspect of the ISO 9126 software quality standard

Based on various limitations possessed by researcher both in terms of time and thought, the Researcher suggested the development of further research, including:

1. There needs to be the improvement in the implementation of the system if applied to the public or internet.

2. There needs to be an improvement in the security of the data system if applied to the public or the internet

\section{References}

[1] C. Naik, F. Hafiz, A. Swain, and A. K. Kar, "Classification of power quality events using wavelet packet transform and extreme learning machine," in 2016 IEEE 2nd Annual Southern Power Electronics Conference (SPEC), 2016, pp. 1-6.

[2] R. Montero, F. Agraz, A. Pages, J. Perello, and S. Spadaro, "Dynamic topology discovery in SDN-enabled Transparent Optical Networks," in 2017 International Conference on Optical Network Design and Modeling (ONDM), 2017, pp. 1-6.

[3] B. H. zul azmi and B. Hayadi, "Design of Expert System to Determine Stock Investment Using Forward Chaining Method," Jour Adv Res. Dyn. Control Syst., vol. 10, no. 10, pp. 1869-1873, 2018.

[4] I. A. Mokhtar, S. Majid, and S. Foo, "Using Information Technology to Improve Health Information Literacy in Singapore - An Exploratory Study," in 2006 ITI 4th International Conference on Information \& Communications Technology, 2006, vol. 0, pp. 1-2.

[5] David Padi, "Vehicular information \& communications technology (VICT) system," in 2009 2nd International Conference on Adaptive Science \& Technology (ICAST), 
2009, pp. 390-394.

[6] G. Gayvoronska, M. Solomitsky, and P. Yatsuk, "The research of the kinetic curve presenting the information and communication technologies' development processes," in 2014 International Conference on Information Science, Electronics and Electrical Engineering, 2014, vol. 2, pp. 923-926.

[7] M. M. S. Danesh, "Comparing the Satisfaction of the E-learning Between Teenagers and People with More than 45 Years Old in Cyberjaya," in 2010 International Conference on e-Education, e-Business, e-Management and e-Learning, 2010, pp. $432-435$

[8] E. Heuel and B. Feldmann, "A new standardisation and certification initiative in elearning-The qualification standard "Certified European E-Tutor," in 2013 Second International Conference on E-Learning and E-Technologies in Education (ICEEE), 2013, pp. 249-253.

[9] A. F. M. Saleh and A. F. A. Farouk, "Students with Disabilities' Attitudes towards ELearning Courses in Developing Countries," in 2013 Fourth International Conference on e-Learning "Best Practices in Management, Design and Development of e-Courses: Standards of Excellence and Creativity,” 2013, pp. 253-257.

[10] S. Ahmed, "The Role of e-Learning to Face the Challenges of the Century," in 2013 Fourth International Conference on e-Learning "Best Practices in Management, Design and Development of e-Courses: Standards of Excellence and Creativity,” 2013, pp. 275-275.

[11] J. G. Martel, "Research and development by electric utilities in Canada," in 2006 IEEE Power Engineering Society General Meeting, 2006, p. 1 pp.

[12] B. Herawan Hayadi, A. Bastian, K. Rukun, N. Jalinus, Y. Lizar, and A. Guci, "Expert System in the Application of Learning Models with Forward Chaining Method," Int. J. Eng. Technol., vol. 7, no. 2.29, p. 845, May 2018. 